\title{
A Pragmatic Analysis of Applying Violating the Maxims to the Yemeni Dialect
}

\author{
Issa Ali Umar Al-Qaderi \\ Department of English, Ibb University, Yemen; \\ Department of Applied Linguistics, University of Warsaw, Poland \\ E-mail: issaalqaderi@gmail.com
}

Received: Nov. 13, 2015 Accepted: Dec. 15, 2015 Published: December 21, 2015

doi:10.5296/ijl.v7i6.8762ＵRL: http://dx.doi.org/10.5296/ijl.v7i6.8762

\begin{abstract}
The prime aim of this research is to investigate Gricean Theory of Conversational Implicature and its application to the Arabic language. For the purpose of investigating such a theory, semi-structured interviews with 15 Yemeni participants were audio-recorded, transcribed, translated and then interpreted . There were four Ph.D. candidates, four M.A. candidates and seven B.A. candidates. Both a qualitative and a quantitative approach were adopted. The analysis focused on violating the conversational maxims. The findings showed that Gricean Theory of Conversational Implicature can be applied to Arabic language, particularly the Yemeni dialect. In addition, the results revealed that the maxim of Quality was most frequently violated. Then the maxims of Quantity, Relation and Manner respectively.
\end{abstract}

Keywords: Conversational Implicature, Conversational maxims, Violating the maxims, Arabic language, Yemeni dialect 


\section{Introduction}

As a matter of fact, languages have appeared for the sake of communication. Speakers and listeners communicate with one another for the purpose of conveying what they want to say either implicitly or explicitly. While conversing, they try to cooperate with one another in order to understand and be understood and this is the core idea of pragmatics.

In the 1970s pragmatics became an integral part of linguistics though it was argued whether it should be regarded as a field of linguistics or philosophy since its first proponents were philosophers such as Austin, Grice and Searle rather than linguists (Collinge, 2001 in Alduais, 2012, p.377). However, in the 1980s, it started to appear in "textbooks on linguistics" (Thomas, 1995 in Alduais, 2012, p.377). The history of pragmatics can be described as a conjunction of different moves, coming from epistemology and semiotics (Morris 1938), philosophy of language (Austin 1962; Searle 1969), logic (Frege [1892]1952; Russell 1905), and linguistics (Horn 1972; Wilson 1975; Kempson 1975; Gazdar 1979). Basic pragmatics was initially linked to reference and presupposition (Frege 1892 and Russell 1905), semantic and pragmatic presuppositions (Wilson and Kempson; Stalnaker 1977), and illocutionary acts (Austin 1962 and Searle 1969), and it was only in the mid-70s that the concept of implicature was introduced in Grice's article "Logic and Conversation" (1975).

Among the most influential pragmatic theories that has captured the attention of the researcher is Gricean Theory of Conversational Implicature. Grice makes a clear distinction between what is said and what is meant. In comparison and with reference to this theory, an empirical study is going to be presented for the purpose of investigating the application of this theory to Arabic language just like English.

\subsection{Gricean Theory of Conversational Implicature}

Basically, Gricean Theory of Conversational Implicature is based on the assumption that interlocutors have some basic goals in common that are governed by the Cooperative Principle. Therefore, Gricean Theory of Conversational Implicature and the Cooperative Principle were proposed to describe how effective communication is achieved in common situations (Terkourafi, 2005, p.1). Frederking (1996, p.1) argues that the Gricean Theory of Conversational Implicature and the Cooperative Principle play a significant role, for some researchers, in thinking about how language works in real use and how implictures get conveyed.

Furthermore, it can be observed that most of the time both speakers and listeners tend to speak cooperatively with one another in order to be understood in a particular way. This observation has been underscored by Bach (2006) when he asserts that "what a speaker means can be divided exhaustively into what is said and what is implicated. Yet what a speaker means can go beyond what he says without being implicated" (p.11).

\subsection{Gricean Cooperative Principle and the Maxims of Conversation}

Grice subdivided his Cooperative Principle into nine maxims of conversation which were meant to explain how implicatures get conveyed. Then he classified these nine maxims into 
four categories: Quality, Quantity, Relation and Manner. They are used, according to Bach (2006, p.5), to explain the relation between utterances and what is understood from them. Bach (2006, p.6) also claims that we, as listeners, assume that the speaker is being cooperative by speaking truthfully, informatively, relevantly and appropriately. If an utterance appears not to conform to any of these presumptions, we look for another way of taking it so that it makes sense.

The Cooperative Principle as well as its four conversation maxims are regarded as a major contribution to the field of pragmatics. They do not only play a significant role in the generation of conversational implicatures, but also are considered a successful example that shows how human communication is governed by the principle.

In his article "Logic and Conversation" (1975), Grice makes a very general distinction between what is said by a speaker and what he means or implicates and he provides us with the definition of Cooperative Principle: "make your contribution such as is required, at the stage at which it occurs, by the accepted purpose of the talk exchange in which you are engaged" (p.45). Therefore, Grice's logic of conversation is based on the idea that contributors to a conversation are rational agents; that is, that they obey a general principle of rationality known as the cooperative principle.

Under the Cooperative Principle, there are four maxims and below each maxim, there are some other sub-maxims (1975, Pp.45-46):

\section{The maxim of Quantity}

- Make your contribution as informative as is required.

- Do not make your contribution more informative than is required.

II. The maxim of Quality

- Do not say what you believe to be false.

- Do not say that for which you lack adequate evidence.

III. The maxim of Relation

- Make your contributions relevant.

IV. The maxim of Manner

- Avoid ambiguity.

- Avoid obscurity of expression.

- Be brief

- Be orderly.

Grice supported the Cooperative Principle with four conversation maxims and he identifies four ways in which discourse participants may break or fail to fulfill maxims in a conversation: flouting, violating, clashing and opting out. (Lindblom, 2001, p.1603). In this research the focus is going to be on violating the maxims.

Pragmatically speaking, Grice, according to Zor (2006, p.23), argues that if people fail to fulfill or observe these maxims during the exchange of conversation, the participant may 
quietly and unostentatiously violate a maxim. This means that the participant does not observe the maxim intentionally for some purposes. Grice (1975, p.320) states that in the case when one quietly and unostentatiously violates a maxim, "one is liable to mislead" as it is illustrated below:

1) Quiet violation of Quality: Saying something you know to be false. The hearer would believe you.

2) Quiet violation of Quantity: Failing to mention all of the relevant information. The hearer would assume that there is nothing more to know.

3) Quiet violation of Relevance: Saying something that is irrelevant. The hearer would assume that it is relevant.

Thus, the investigation is going to be applied to Arabic language, particularly the Yemeni dialect and this is going to be the prime objective of this research.

\subsection{An Overview of Yemeni Arabic}

In comparison and with reference to comparative linguistics, Arabic language is one of the Semitic languages and is classified into five forms, namely: 1) Classical Arabic Language; 2) Standard Arabic language; 3) Modern Standard Arabic language; 4) Spoken Arabic language; and finally 5) Foreign Arabic language (Alduais 2012 in Al-Qaderi, 2015, p. 22).

Basically, within each language there are several dialects and each dialect has its own characteristics and all of them share a set of linguistic characteristics that make up the language independent of other languages (Al-Najjar 2013 in Al-Qaderi, 2015, p. 25).

As one of the Arabic dialects, Yemeni Arabic is considered to be one of the Arabic varieties spoken in Yemen. It is used for daily communication and has no official status. It is also worth stating that almost all Yemeni citizens speak Arabic. However, there are various dialects within Yemeni Arabic each with its own vocabulary and phonology. The most important of these dialects are Sana'ani, Adeni, Ibbi, Ta'zzi, Tihami and Hadhrami. The most noticeable difference lies in the distinction between the dialect of the northern part of Yemen and that of the southern part of Yemen (Al-Qaderi, 2015, p. 31).

\section{Method}

After an intensive reading of various research approaches, the author has found that the most appropriate research approach that would achieve the aim of the study was the qualitative approach. This approach seems to be appropriate since it requires individual interviews, focus groups, observations, a review of existing literature, or a number of theses. This idea is also highlighted by Hancock and Algozzine's (2006) following statement:

The individual interviews and focus groups inherent in qualitative research may slow one's research efforts if access to individuals is difficult. It is also worth mentioning that in qualitative research, the goal is to understand the situation under investigation primarily from the participants' and not the researchers' perspective. (p.7)

Within this approach, the author will focus on a case study in which semi-structured 
interviews were designed to investigate the study participants' responses. The semi-structured questions and the consent form were translated into the participants' mother tongue (Arabic). The data were then transcribed and translated from Arabic into English.

After being analyzed qualitatively, a quantitative approach is going to be taken on. In other words, all the collected data that were analyzed qualitatively is going to be analyzed quantitatively by means of presenting some tables and figures.

\subsection{Participants}

This study was conducted in Warsaw city in Poland. All the chosen participants were interviewed individually in the dormitories wherein they live.

The participants of this study were classified into three groups. First consists of Ph.D. candidates $(n=4)$, second of M.A. candidates $(n=4)$, and the third and the last one was composed of undergraduate candidates $(n=7)$.

The Ph.D. candidates were selected and classified as the first group of the study participants. They were four candidates who are currently enrolled at the University of Warsaw, Poland. They were given these labels: Participant 1, Participant 2, Participant 3, and Participant 4.

The M.A. candidates were classified as the second group of the study participants. They were also four candidates who are currently enrolled at the University of Warsaw, Poland. They were given these labels: Participant 5, Participant 6, Participant 7, and Participant 8.

The undergraduate candidates were classified as the third and the final group of the study participants. They were seven candidates who are currently enrolled at the University of Warsaw, Poland. They were given the following labels: Participant 9, Participant 10, Participant 11, Participant 12, Participant 13, Participant 14and Participant 15.

\subsection{Data-collection Instruments}

Data-collection instruments in qualitative research are various. One of these instruments is interviewing. Interviews are considered a very effective instrument for expressing ideas, beliefs, knowledge, etc. Seidman (2006) states that "...interviewing is an interest in understanding the lived experience of other people and the meaning they make of that experience" (p.10). Therefore, fifteen semi-structured interviews have been designed for the three groups. Each group had its own questions. The questions used differ from one group to another because they were not of the same educational level and age. There are, on the other hand, some similar questions which were used to get some personal information. These general questions were used to break the ice before moving to the more specific ones.

\subsection{Data-collection Procedures}

When the interview questions were ready, the author tested the audio-recording tool in order to make sure that it was picking up the sounds clearly and could record for a long time. After that, the participants were contacted by phone and they agreed to be interviewed. After making appointments with the interviewees, the author went to their dormitories wherein they live. A consent form was prepared to introduce the study and to inform the interviewees how 
they could participate in the study. The consent form was personally given to them before the interviews and was taken back signed. The Arabic language (Yemeni dialect) was used during the interviews. Each interview lasted for about fifteen minutes.

\subsection{Data Analysis}

The participants were given pseudonyms in order to protect their anonymity. The transcripts were organized and separated in separate files to make the analysis process easier. Each participant was given a separate file. These files encompassed all the data needed to be analyzed. After printing all the fifteen files in both languages, they were given to another researcher in order to check the translation. This was very important since it led to accuracy and reliability. After receiving the feedback, the author made all the necessary changes and started examining the whole translated data closely in order to select the most important extracts that can be used to investigate the Gricean Theory of Conversational Implicature.

After transcribing and translating the data, the author started going through the transcripts intensively many times that resulted in marking and segmenting the most important utterances/extracts that might answer the questions of the study.

These classifications were coded by giving them some letters that refer to the whole words. For instance, the author used VMM as a code for violating the maxim of Manner. This kind of coding was used for the whole segments. Next, the number of violating of each maxim in each interview was identified.

To cut the long story short, the data are presented with further interpretation (qualitatively) and tables and figures (quantitatively) in the following section.

\section{Results and Discussion}

This section presents a qualitative and quantitative analysis of the data collected from the study participants. The first subsection presents an interpretational analysis that deals with violating the maxims. The author has selected twelve illustrative examples to be analyzed pragmatically. They were first given in Arabic. Then an English translation was given to them as well. The second subsection takes on a quantitative approach.

\subsection{Qualitative Analysis}

\subsubsection{Violating the Maxims}

Violating maxims constitutes a deliberate attempt by the speaker to mislead his or her interlocutor(s). The participant does not observe the maxim intentionally for some purposes.

\section{Example (1): (source in Arabic)}

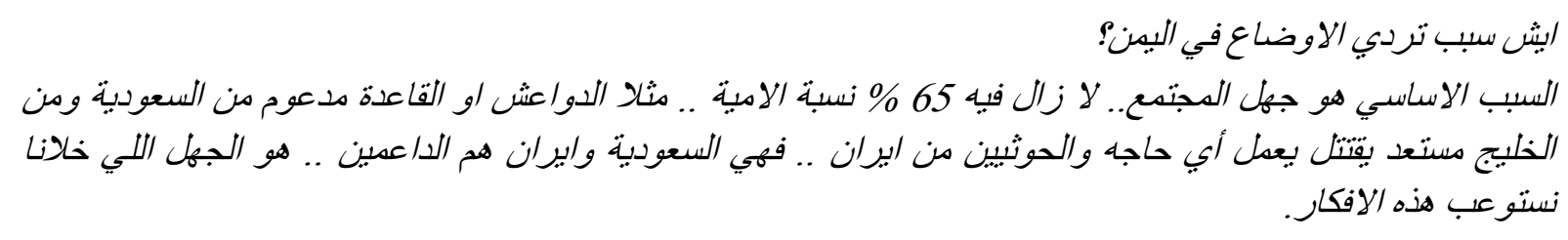

Example (1): (translated into English) 
Interviewer: What are the reasons that cause all the current problems in Yemen?

Participant 4: The prime reason is the society's ignorance. There is still 65\% of illiteracy. For instance, ISIS or Al-Qaida are supported by KSA whereas AlHuthi is supported by Iran. Therefore, it is our ignorance which paved the way for the outside powers to intervene with our matters. It is ignorance which leads us to accept these agendas/ideas.

In this example, the participant was asked about the reasons behind the current situation in Yemen. His answer started stating that it is the society's ignorance and illiteracy that constitutes $65 \%$. This piece of information lacks evidence and it is not sure whether it is true or not and therefore the maxim of Quality was violated.

Example (2): (source in Arabic)

$$
\text { الوضش رايك بأوضاع اليسن حالياء }
$$

Example (2): (translated into English)

Interviewer: What do you think of the current situation in Yemen?

Participant 1: It's all right. The media may show it badly. It's quite natural. There are some problems. If you search for them, you will find them.

In this example, the participant was asked about his point of view about the current situation in Yemen. His answer seemed to violate the maxim of Quality since it contained untrue information. For instance, he stated that the current situation in Yemen is "quite natural". This has been done purposefully in order to mislead the interviewer. Both interlocutors know very well that nowadays Yemen is living critical moments and there are lots of problems that threaten its stability.

Example (3): (source in Arabic)

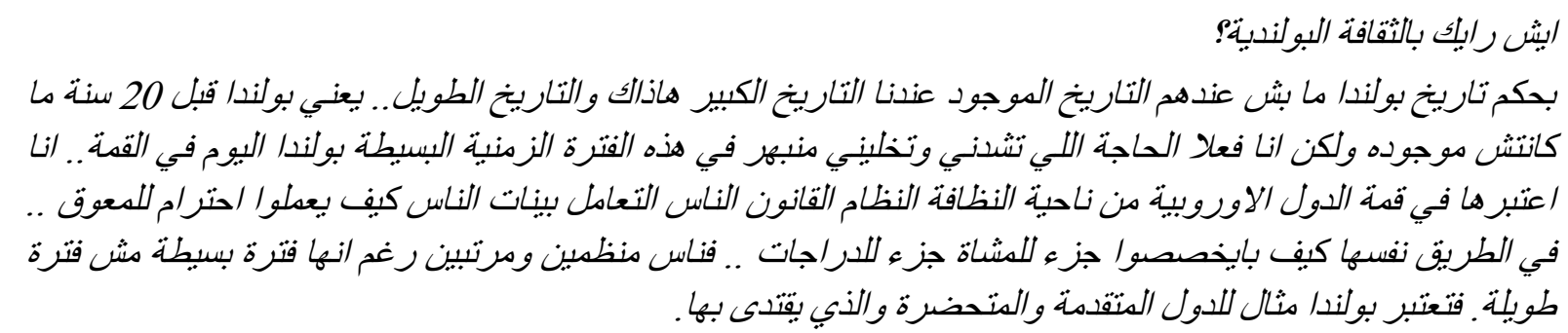

\section{Example (3): (translated into English)}

Interviewer: What do you think of the Polish culture?

Participant 8: Poland has not a long history like the one that is found in our country. I mean that before 20 years Poland did not exist. But what has captivated my attention is the progress it has accomplished in a very short time. I consider it on the top of the European countries in terms of cleanliness, system, law, the Polish people are so respectful especially to those handicapped. On the road they specify a part for pedestrian and the other for bicycles.

In this example, the interviewer asked about the participant's opinion about the Polish culture. The maxim of Quality was violated here because the participant's answer included a piece of 
information that is untrue and has no adequate evidence. For instance, he stated that "Poland has not a long history...before 20 years Poland was not existed". The interviewer, on the other hand, noticed that the participant was trying to mislead him by providing such untrue and unproven information.

\section{Example (4): (source in Arabic)}

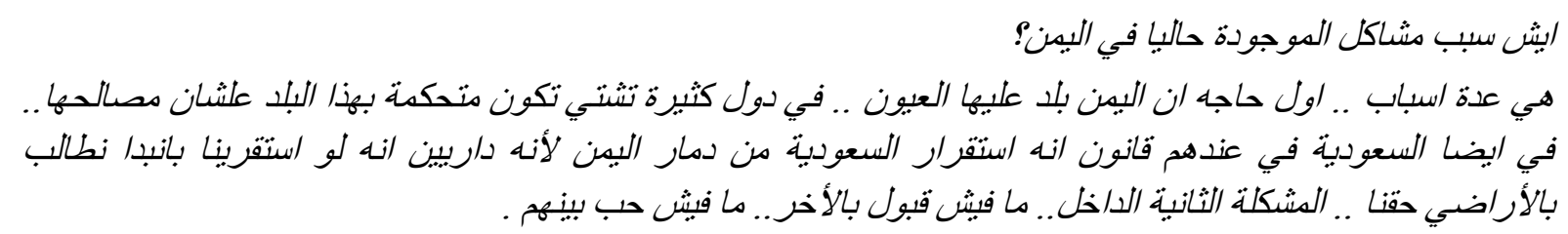

\section{Example (4): (translated into English)}

Interviewer: What are the reasons that cause all the current problems in Yemen?

Participant 8: Many reasons. First of all, there are many countries which desire to control it because of their interests. Also, in the KSA they have got a law which says that KSA's stability lies in destroying Yemen. The second thing is that there is no coexistence among each other. No love.

Similarly, the maxim of Quality was violated in this example. The participant was asked about the reasons behind the current situation in Yemen. However, his answer included a false piece of information that lacks adequate evidence. For instance, he stated that "in the KSA they have got a law which says that KSA's stability lies in destroying Yemen". This cannot be believed unless it is provided with evidence that proves that it is correct and this law is existed/available. The interviewer, on the other hand, noticed that the participant was trying to mislead him because he might not like the KSA or he is just trying to philosophize his view by saying something that is not based on an authentic source.

\section{Example (5): (source in Arabic)}

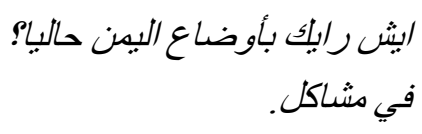

\section{Example (5): (translated into English)}

Interviewer: What do you think of the current situation in Yemen?

Participant 6: There are problems.

In this example, the maxim of Quantity was violated because the participant's answer was not informative enough. The interviewer asked the participant about his opinion regarding the current situation in Yemen. The participant stated that "[t[here are problems". By stating so, it seems that the participant had done this intentionally in order to invite the interviewer to infer the conversational implicature 'you must know everything. There is no need to repeat it'.

Example (6): (source in Arabic)

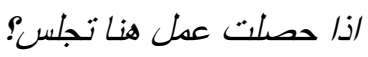

\section{Example (6): (translated into English)}

Interviewer: Are you willing to stay in Poland in case you find a work?

Participant 13: Yes. 
In this example, the maxim of Quantity was violated because the participant's answer was not informative enough. The interviewer asked the participant about whether he is willing to stay in Poland if he finds a work after finishing his study. The answer was "yes". This answer was not informative enough and it was said purposefully to invite the interviewer to infer the implicature 'as long as the situation in Yemen is so bad nowadays, I'd rather stay here and search for a job'.

Example (7): (source in Arabic)

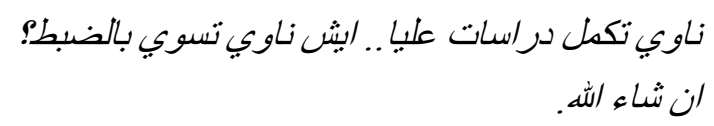

\section{Example (7): (translated into English)}

Interviewer: Are you planning to pursue your higher studies? Can you tell me about your future plans please?

Participant 12: Hopefully.

Similarly, in this example the maxim of Quantity was violated. The interviewer asked the participant whether he is planning to pursue his higher studies and to tell him a little bit about his future plans. The answer was "hopefully". It means that the participant's answer was insufficiently informative and this had been done purposefully and because of this the maxim of Quantity was violated. Based on the contextual knowledge of both interlocutors, the interviewer could extract the implicature 'so long as I am doing great in my undergraduate program, it would be natural that I am going to pursue my higher studies'.

Example (8): (source in Arabic)

مخطط تبتزوج بولنديةٌ

\section{Example (8): (translated into English)}

Interviewer: Are you planning to marry a Polish girl?

Participant 14: Frankly speaking, it depends. You know every human being is born on instinct and we may have gone away from this instinct. But when you come across the right partner and try to approximate between opinions and theories, perhaps you will find your way, both of you. I know that she will have a different culture from mine, but we can compromise things and live happily.

In this example, the interviewer asked the participant whether he is planning to marry a Polish girl in the future. The answer included some pieces of information that seemed to be unrelated to the question being asked. The participant seemed to go off topic especially when he started to talk about the human instinct in the beginning of his answer. This means that he was trying to mislead the interviewer by providing irrelevant information so that he can deviate answering the question directly.

Example (9): (source in Arabic)

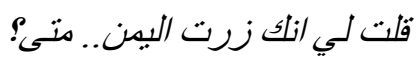


رجعت السعودية كان معي عمل في الرياض.. ورجعت اعتمرت وزرت النبي صلى الله وعلية وسلم.. وروحت اليمن فعلت شهر ونص في صنعاء.

\section{Example (9): (translated into English)}

Interviewer: You said that you had been to Yemen, when?

Participant 3: I travelled to Saudi Arabia because I had some work to do there. After that, I did Omrah and visited the tomb of our prophet Muhammad (Peace Be upon Him). Then I headed to Yemen and stayed there for about a month and a half in Sana'a.

In this example, the maxim of Relation was violated once again. The interviewer asked the participant about the time of his visit to Yemen. However, the participant's answer included some irrelevant information. For instance, he started talking about his visit to Saudi Arabia because of having some work to do there. Then he went to do Omrah (a religious event). After that he stated that he had stayed in Yemen for about a month and a half without mentioning when he did visit it exactly. This means that the participant is trying to hide the correct answer by mentioning unrelated information.

Example (10): (source in Arabic)

$$
\begin{aligned}
& \text { في صعوبات واجناتك الى الان في البحث: }
\end{aligned}
$$

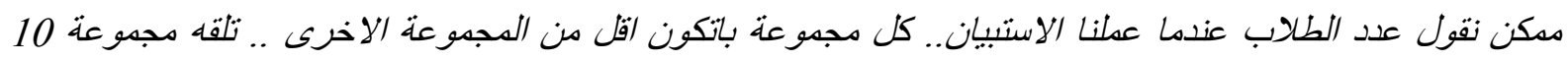

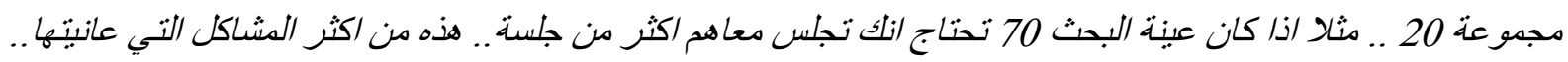

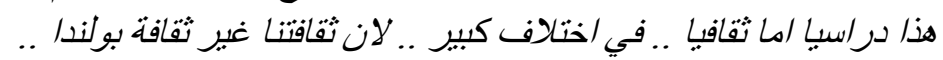

\section{Example (10): (translated into English)}

Interviewer: What are the difficulties you encountered while writing your thesis?

Participant 1: The lack of students when needed to work out the questionnaire. They are divided into groups and each group has less number than the other. For example, if the research sample is 70, you need to sit with them more than once. This is one of the major difficulties I am facing... this is in terms of the study/educational difficulties. Concerning the cultural difficulties, there is a big difference between the Polish culture and ours.

In this example, the maxim of Relation was violated because the participant's answer included irrelevant information to the context. The interviewer asked the participant about the difficulties he had encountered during writing his thesis. The participant's answer started talking about one of the major difficulties which is the sample of the study and abruptly changed the topic by talking about the Polish culture. This means that the participant does not want to refer to the other difficulties he is facing like finding sources or working with his supervisor, etc. This abrupt change indicates violating the maxim of Relation.

Example (11): (source in Arabic)

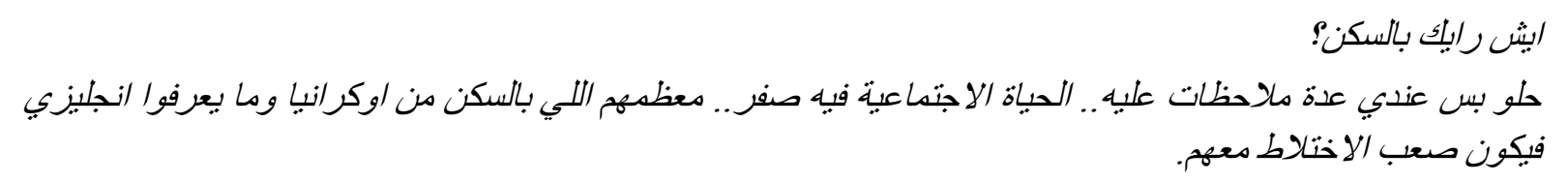

\section{Example (11): (translated into English)}

Interviewer: How do you find your accommodation?

Participant 7: It's nice, but I have some comments. The social life is zero. Most of the inhabitants are from Ukraine and they cannot speak English. It is difficult to socialize. 
In this example, the maxim of Relation was violated. The interviewer asked the participant's opinion about his accommodation not about the neighbors and the surroundings. However, the answer included irrelevant information. For instance, the participant talked about the inhabitants of the accommodation instead of talking about the accommodation itself according to the question being asked. This means that the participant was trying to mislead the interviewer by changing the focus to the inhabitants of the accommodation and to invite the interviewer to extract the implicature 'he is not happy with the inhabitants of the accommodation'. To put it simple, in this example the interviewer's question had two different interpretations. One interpretation, which was understood by the interviewer, was concerned with the addressee's opinion about his accommodation, for example, its location and quietness. Another interpretation, which was understood by the addressee, was related to the addressee's opinion about the neighbors and surroundings of the accommodation. These two interpretations proved that the addressee was still cooperative.

Example (12): (source in Arabic)

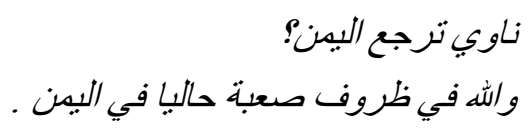

\section{Example (12): (translated into English)}

Interviewer: Are you planning to go back home?

Participant 6: Actually, the current situation in Yemen is so bad.

In this example the interviewer asked the participant whether he is planning to go back home the moment he finishes his study. The answer, however, was not clear and did not satisfy the curiosity of the interviewer. The participant stated that "the current situation in Yemen is so bad ". This answer violated the maxim of Manner because the participant did not want to supply the interviewer with more information why he did not plan to go back home/Yemen. He wanted the interviewer to infer the implicature 'as long as the situation in Yemen is so bad, it is for sure that I will not go back home and I will try to find a job and stay here in Poland'.

To conclude, after discussing the analysis of the data of this study qualitatively, the following subsection is going to present the main findings of this study quantitatively in detail.

\subsection{Quantitative Analysis}

\subsubsection{Violating the Maxims}

Violating the maxims is also considered an integral part of each interview. The number of maxims violated in each interview is illustrated in the following table:

Table 1. Number of Maxims Violated in Each Interview

\begin{tabular}{|l|l|l|l|l|l|l|l|l|l|l|l|l|l|l|l|l|}
\hline Interviews & 1 & 2 & 3 & 4 & 5 & 6 & 7 & 8 & 9 & 10 & 11 & 12 & 13 & 14 & 15 & Total \\
\hline Quality & 1 & 0 & 1 & 3 & 0 & 0 & 2 & 0 & 0 & 0 & 0 & 0 & 0 & 0 & 0 & 7 \\
\hline Quantity & 0 & 0 & 0 & 0 & 0 & 0 & 0 & 2 & 1 & 1 & 1 & 0 & 1 & 0 & 0 & 6 \\
\hline Relation & 0 & 1 & 0 & 0 & 1 & 0 & 1 & 0 & 0 & 0 & 0 & 0 & 1 & 0 & 0 & 4 \\
\hline Manner & 0 & 0 & 0 & 0 & 0 & 0 & 0 & 1 & 0 & 0 & 0 & 0 & 0 & 0 & 0 & 1 \\
\hline Total & 1 & 1 & 1 & 3 & 1 & 0 & 3 & 3 & 1 & 1 & 1 & 0 & 2 & 0 & 0 & 18 \\
\hline
\end{tabular}




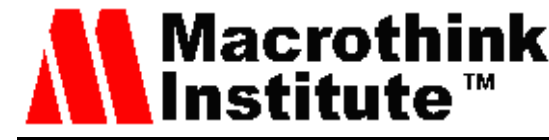

In detail, the above table illustrates that it was the maxim of Quality that was most frequently violated. It was violated 7 times in all the interviews. The participants of this study underscored that most of what they said was not true or lacked adequate evidence. Second, the maxim of Quantity was violated 6 times. This means that some of the participants of the study were not brief and to the point in their answers. They provided either more or less information to the questions being asked. Third, the maxim of Relation was violated 4 times in all the interviews. Some of the participants of the study intended to say something that was not related to the questions being asked. Their answers included some irrelevant information. Finally, the maxim of Manner was violated just one time in all of the interviews. This means that the participants were careful not to say anything ambiguous or obscure or not orderly. The following figure displays the number of maxims violated in each interview:

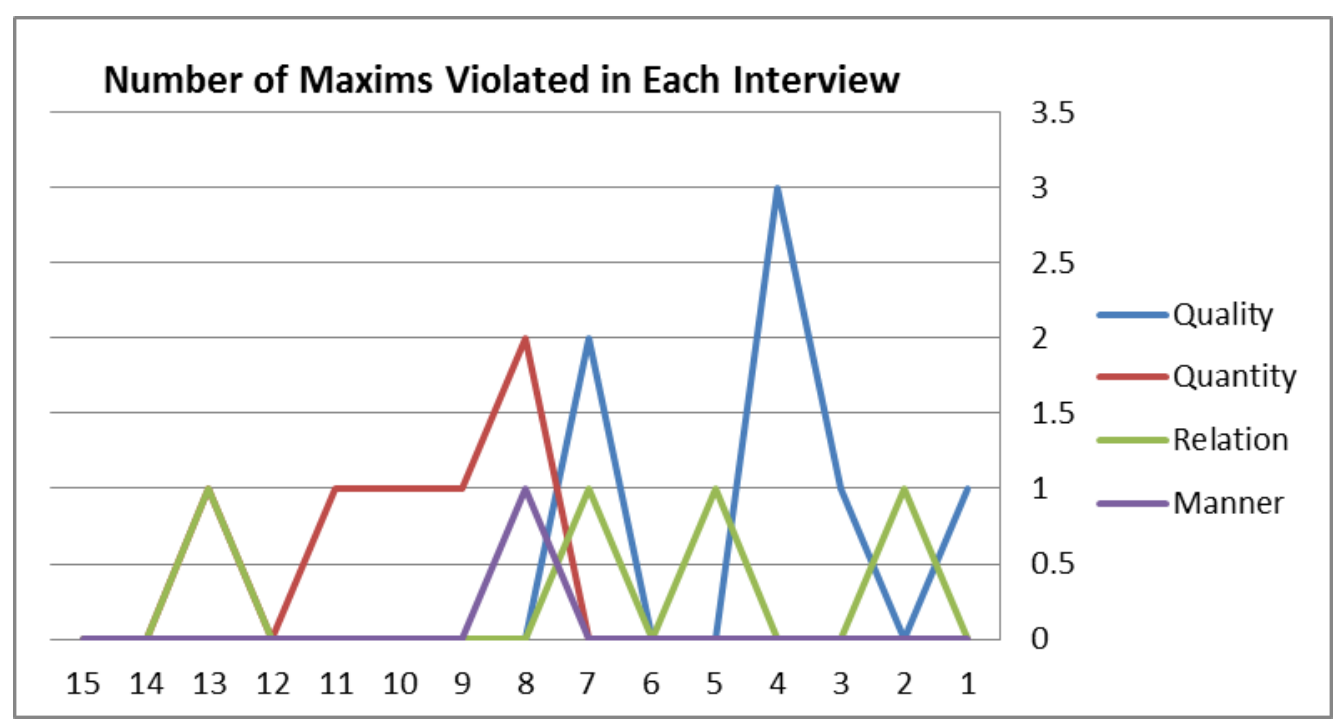

Figure 1. Number of Maxims Violated in Each Interview

This figure illustrates how often the maxim of Quality was violated. The blue line shows the number of maxim of Quality violations in each interview. It can be seen that the maximum instances the maxim of Quality was violated was 3 times (in the interview number four). Second, the figure displays how the maxim of Quantity was violated (brown line). It was violated the maximum of 2 times (in the interview number eight). Third, the maxim of Relation (green line) was violated in each interview no more than once (in the interviews number two, five, seven and thirteen). The maxim of Manner (purple line) was violated only once (in the eighth interview).

\section{Conclusion}

The aim of this research was to investigate Gricean Theory of Conversational Implicature and its application to Arabic language. The data were collected from 15 Yemeni participants who had different academic levels and different dialectal backgrounds and gathered through semi-structured interviews. The interviews were transcribed, translated, organized and interpreted. The focus was on violating the maxims. The results showed that the maxim of 


\section{$\underline{\text { Macrothink }}$}

International Journal of Linguistics ISSN 1948-5425 2015, Vol. 7, No. 6

Quality was most frequently violated. Then the maxims of Quantity, Relation and Manner respectively.

\section{Acknowledgement}

This paper is part of my MA thesis that I accomplished at the Dept. of Applied Linguistics, University of Warsaw and directed by Prof. Dr. Agata Klimczak-Pawlak. All words of thanks in all languages cannot express my sincere appreciation to her and all the participants of this study. Needless to say, many thanks go to the two anonymous reviewers for their insightful and related comments. I will be most grateful to them forever and a day.

\section{References}

Alduais, A. (2012). Conversational Implicature (Flouting the Maxims): Applying Conversational Maxims on Examples Taken from Non-Standard Arabic Language, Yemeni Dialect, an Idiolect Spoken at IBB City. Journal of Sociological Research, 3(2), 376-387. http://dx.doi.org/10.5296/jsr.v3i2.2433_

Al-Qaderi, I. (2015). Pragmatics in Arabic: Investigating Gricean Theory of Conversational Implicature in Arabic Data: an Empirical Study. Saarbrucken, Deutschland / Germany: LAP Lambert Academic Publishing.

Bach, K. (2006). The top 10 misconceptions about implicature. Drawing the Boundaries of Meaning: Neo-Gricean studies in pragmatics and semantics in honor of Laurence R. Horn, 21-30. http://dx.doi.org/10.1075/slcs.80.03bac

Frederking, R. (1996). Grice's maxims: do the right thing. In Proceedings of the Computational Implicature Workshop at the AAAI-96 Spring Symposium Series, Stanford, CA. $1-6$

Grice, H. P. (1975). Logic and Conversation. Cambridge: Cambridge University Press. Pp.45-46.

Hancock, D., \& Algozzine, R. (2006). Doing case study research: A practical guide for beginning researchers. New York: Teachers College Press.

Lindblom, K. (2001). Cooperating with Grice: A cross-disciplinary metaperspective on uses of Grice's cooperative principle. Journal of Pragmatics, 33(10), 1601-1623. http://dx.doi.org/10.1016/s0378-2166(00)00069-2_

Seidman, I. (2006). Interviewing as qualitative research: A guide for researchers in education and the social sciences (3rd ed.). New York: Teachers College Press, Columbia University.

Terkourafi, M. (2005). Socialising Grice: On interlocutors' reasons for co-operating in conversation. Cambridge Occasional Papers in Linguistics (COPIL), 2, 235-247.

Zor, B. (2006). Using Grice's Cooperative Principle and Its Maxims to Analyze Problems of Coherence in Turkish and English Essays (Unpublished doctoral dissertation). Middle East Technical University, Turkey. 


\section{Appendices}

A. Interview Questions for Ph.D. Candidates

1- $\quad$ Please tell me your name.

2- Please tell me how old you are.

3- $\quad$ Please tell me where you are from.

4- Please tell me about your marital status.

5- Please tell me how many languages you speak?

6- Where do you study?

7- What do you study?

8- What program are you enrolled in?

9- I wonder if you please let me know how you got the scholarship.

10- What is the title of your thesis?

11- What are the difficulties you encountered while writing your thesis?

12- Have you got any publications?

13- How long have you been in Poland?

14- What do you think of Poland?

15- What do you think of the Polish language?

16- What do you think of the Polish culture?

17- When are you supposed to finish your studies?

18- Are you planning to go back home?

19- Are you planning to be an academic?

20- Are you willing to stay in Poland in case you find a work?

21- Where did you get your B.A. and M.A., which major?

22- Based on your experience, what is the difference between studying in Yemen and Poland?

23- What do you think of the current situation in Yemen?

24- What are the reasons that cause all the current problems in Yemen?

25- Where do you live nowadays?

26- How do you find your accommodation?

27- How did you spend your Christmas break?

28- What are you planning to do in the Easter time?

29- What do you think of this year's winter compared to the previous years'?

30- How much money do you have in your bank account?

\section{B. Interview Questions for M.A. Candidates}

1- $\quad$ Please tell me your name.

2- Please let me know how old you are.

3- Please tell me where you are from.

4- Please tell me about your marital status.

5- Please tell me how many languages you speak?

6- Where do you study?

7- What do you study? 
8- What program are you enrolled in?

9- How did you get the scholarship?

10- What is the title of your dissertation?

11- What are the difficulties you encountered while writing your dissertation?

12- How long have you been in Poland?

13- What do you think of Poland?

14- What do you think of the Polish language?

15- What do you think of the Polish culture?

16- When are you supposed to finish your studies?

17- Are you planning to go back home?

18- Are you planning to pursue your Ph.D. program?

19- Are you willing to stay in Poland in case you find a work?

20- Where did you get your B.A.?

21- Based on your experience, what is the difference between studying in Yemen and Poland?

22- How many courses did you take in the first semester?

23- What do you think of the current situation in Yemen?

24- What are the reasons that cause all the current problems in Yemen?

25- Where do you live nowadays?

26- How do you find your accommodation?

27- How did you spend your Christmas break?

28- What are you planning to do in the Easter time?

29- What do you think of this year's winter compared to the previous years'?

30- When are you planning to get married?

31- Based on your own perspective, what are the characteristics you prefer to be in your would-be wife/husband?

32- How much money do you have in your bank account?

\section{Interview Questions for Undergraduate Candidates}

1- $\quad$ Please tell me your name.

2- Please let me know how old you are.

3- Please tell me where you are from.

4- Please tell me how many languages you speak?

5- Where do you study?

6- What do you study?

7- What program are you enrolled in?

8- How did you get the scholarship?

9- What did you study in Yemen?

10- How long have you been in Poland?

11- What do you think of Poland?

12- What do you think of the Polish language?

13- What do you think of the Polish culture?

14- When are you supposed to finish your studies? 
15- Are you planning to go back home?

16- Are you planning to pursue your higher studies?

17- Are you willing to stay in Poland in case you find a work?

18- Based on your experience, what is the difference between studying in Yemen and Poland?

19- How many courses did you take in the first semester?

20- What do you think of the current situation in Yemen?

21- What are the reasons that cause all the current problems in Yemen?

22- Where do you live nowadays?

23- How do you find your accommodation?

24- How did you spend your Christmas break?

25- Did you find a difference between celebrating here and in Yemen?

26- What are you planning to do in the Easter time?

27- What do you think of this year's winter compared to the previous years'?

28- When are you planning to get married?

29- Are you planning to marry a Polish girl?

30- Based on your own perspective, what are the characteristics you prefer to be in your would-be wife/husband?

31- How much money do you have in your bank account?

\section{Copyright Disclaimer}

Copyright for this article is retained by the author(s), with first publication rights granted to the journal.

This is an open-access article distributed under the terms and conditions of the Creative Commons Attribution license (http://creativecommons.org/licenses/by/3.0/). 